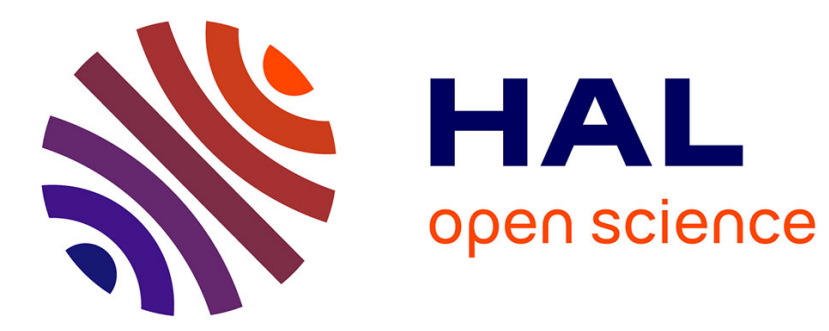

\title{
Defining yield policies in a viability approach
}

L. Chapel, Guillaume Deffuant, S. Martin, C. Mullon

\section{To cite this version:}

L. Chapel, Guillaume Deffuant, S. Martin, C. Mullon. Defining yield policies in a viability approach. Ecological Modelling, 2008, 212 (1-2), p. 10 - p. 15. 10.1016/j.ecolmodel.2007.10.007 . hal-00454451

\section{HAL Id: hal-00454451 \\ https://hal.science/hal-00454451}

Submitted on 8 Feb 2010

HAL is a multi-disciplinary open access archive for the deposit and dissemination of scientific research documents, whether they are published or not. The documents may come from teaching and research institutions in France or abroad, or from public or private research centers.
L'archive ouverte pluridisciplinaire HAL, est destinée au dépôt et à la diffusion de documents scientifiques de niveau recherche, publiés ou non, émanant des établissements d'enseignement et de recherche français ou étrangers, des laboratoires publics ou privés. 


\section{Defining Yield Policies in a Viability Approach}

Laetitia Chapel $^{1}$, Guillaume Deffuant ${ }^{1}$, Sophie Martin ${ }^{1}$ and Christian Mullon ${ }^{2}$

${ }^{1}$ Cemagref, LISC, 24 avenue des Landais, 63172 Aubière Cedex, France, phone: 33 (0)4 734406 00, fax: 33 (0)4 73440696 ,

${ }^{2}$ IRD, GEODES, France, christian.mullon@wanadoo.fr

7

8

\section{Abstract}

10Mullon et al. (2004) proposed a dynamical model of biomass evolution in the Southern 11Benguela ecosystem, including five different groups (detritus, phytoplankton, zooplankton, 12pelagic fish and demersal fish). They studied this model in a viability perspective, trying to 13assess, for a given constant yield, whether each species biomass remains inside a given 14interval, taking into account the uncertainty on the interaction coefficients. Instead of studying 15the healthy states of this marine ecosystem with a constant yield, we focus here on the yield 16policies which keep the system viable. Using the mathematical concept of viability kernel, we 17examine how yield management might guarantee viable fisheries. One of the main practical 18difficulties up to now with the viability theory was the lack of methods to solve the problem 19in large dimensions. In this paper, we use a new method based on SVMs, which gives this 20theory a larger practical potential. Solving the viability problem provides all yield policies (if 21 any) which guarantee a perennial system. We illustrate our main findings with numerical 22simulations.

23Key words: Viability theory, marine ecosystem, fisheries management, Support Vector 24Machines. 


\section{Introduction}

26The viability theory (Aubin, 1991) aims at controlling dynamical systems with the goal to 27maintain them inside a given set of admissible states, called the viability constraint set. Such 28problems are frequent in ecology or economics, when systems die or badly deteriorate if they 29leave some regions of the state space. For instance Béné et al. (2001) studied the management 30 of a renewable resource as a viability problem. They pointed out irreversible overexploitation 31related to the resource extinction. Bonneuil (2003) studied the conditions the prey-predator 32 dynamics must satisfy to avoid extinction of one or the other species as a viability problem. 33Cury et al. (2005) consider viability theory to advise fisheries.

34Mullon et al., (2004) proposed a dynamical model of biomass evolution of the Southern 35Benguela ecosystem, involving five different groups (detritus, phytoplankton, zooplankton, 36pelagic fish and demersal fish). They studied this model in a viability perspective (Aubin, 371991), trying to assess, for a given constant yield, whether each species biomass remains 38inside a given interval, taking into account the uncertainty on the interaction coefficients. The 39aim was to identify constant yield values that allow persistence of the ecosystem. We extend 40the problem and we focus here on the yield policies which keep the system viable, instead of 41 considering a constant yield.

42Using the mathematical concept of viability kernel, we examine how yield management might 43guarantee viable fisheries. The viability kernel designates the set of all viable states, i.e. for 44which there exists a control policy maintaining them within the set of constraints. Outside the 45viability kernel, there is no evolution which prevents the system from collapsing. Aubin 46(1991) proved the viability theorems which enable to determine the viability kernel, without 47considering the combinatorial exploration of control actions series. These theorems also 48provide the control functions that maintain viability. 
49This general approach shows several interesting specific aspects:

50 - It can take into account the uncertainties on the parameters which are generally high in

51 ecosystem modelling. Here, we manage the uncertainties like in (Mullon et al. 2004).

52 - The viability kernel can define a variety of different policies, which respect the 53 viability constraints. Therefore, it offers more possibilities for negotiations and 54 discussions among the concerned stakeholders than techniques which propose a single $55 \quad$ optimal policy.

56The main limitation of the viability approach is its computational complexity. The existing 57algorithm for viability kernel approximation (Saint-Pierre, 1994) supposes an exhaustive 58 search in the control space at each time step. This makes the method impossible to use when 59the control space is of a 51 dimensions like in our problem. Mullon et al. (2004) solved this 60problem with a method which is only adapted to linear equations of evolution. Here, we use a 61new method, based on support vector machines, which can be applied to non-linear models as 62well (Deffuant et al. 2007).

63We present the viability model of the Southern Benguela ecosystem and we recall the main 64concepts of the viability theory. Then, we describe our main numerical results. We show the 65shape of the found viability kernel, and the corresponding possible yield policies. Finally, we 66discuss the results and draw some perspectives.

\section{The viability model of the Southern Benguela ecosystem}

68Following a classical approach (Walters and Pauly, 1997), we suppose that the variation of 69the biomass of species $i$ due to its predation by other species $j$ depends linearly on the 70recipient and donor biomasses $\left(B_{j}\right.$ and $\left.B_{i}\right)$, with respective coefficients $r_{j i}$ and $d_{j i}$. The biomass 71 lost by species $i$ due to the predation by the other species is expressed by equation (1): 


$$
\frac{d B_{i}(i \rightarrow)}{d t}=-\sum_{j}\left(r_{j i} B_{j}+d_{j i} B_{i}\right) .
$$

72The variation of the donor biomass $B_{i}$ due to this interaction takes into account the 73assimilation of the biomass of other species $j$, multiplied by a growth efficiency coefficient 74(denoted below by $g_{i}$ ). Therefore, the biomass gained by species $i$, because of its consumption 75of other species, is expressed by:

$$
\frac{d B_{i}(i \leftarrow)}{d t}=g_{i} \sum_{j}\left(r_{i j} B_{i}+d_{i j} B_{j}\right) .
$$

76For the detritus, the variation of the biomass follows the same principle, but it also integrates 77the non-assimilated biomass of the other species, except phytoplankton, which is added to the 78detritus biomass $B_{1}$ (multiplied by its growth efficiency $g_{1}$ ):

$$
\frac{d B_{1}(\text { non }- \text { assimilated })}{d t}=\sum_{j>r} \sum_{k} g_{1}\left(1-g_{l}\right)\left(r_{l k} B_{l}+d_{k l} B_{k}\right) .
$$

79The model of the Southern Benguela ecosystem considers trophic interactions (predation, 80consumption and catch) among 5 components: detritus $(i=1)$, phytoplankton $(i=2)$, 81zooplankton $(i=3)$, pelagic fish $(i=4)$, demersal fish $(i=5)$. In total, the biomass evolution 82can be written as follows:

$$
\begin{gathered}
\quad \frac{d B_{1}}{d t}=\frac{d B_{1}(\backslash \leftarrow)}{d t}-\frac{d B_{1}(\backslash \rightarrow)}{d t}+\frac{d B_{1}(\text { non }- \text { assimilated })}{d t}-Y_{1} \\
\left\{\begin{array}{l}
\frac{d B_{i}}{d t}=\frac{d B_{i}(i \leftarrow)}{d t}-\frac{d B_{i}(i \rightarrow)}{d t}-Y_{i} . \\
\text { 83where } g_{i} \text { is the growth efficiency of species } i, Y_{i} \text { is the yield of species } i \text {. Figure } 1 \text { shows the }
\end{array}\right.
\end{gathered}
$$
84 structure of the ecosystem.

86Mullon et al. (2004) take into account the uncertainty on parameters $r_{i j}$ and $d_{i j}$, which is 87expressed by: 


$$
r_{i j} \in\left\lfloor\bar{r}_{i j}-\delta r_{i j}, \bar{r}_{i j}+\delta r_{i j}\right\rfloor, d_{i j} \in\left\lfloor\bar{d}_{i j}-\delta d_{i j}, \bar{d}_{i j}+\delta d_{i j}\right\rfloor
$$

88They consider this model in a viability perspective, in order to study the persistence of the 89 ecosystem and to define the impact of the fisheries. Given a constant yield, they define 90scenarios which result is a "healthy" system.

91Extending the work of (Mullon et al., 2004), we incorporate the fisheries in this study as a 92control variable of the system, in order to find the yield policies which allow keeping the 93system viable. To guarantee a perennial system, the viability constraints are defined by:

$$
\left\{\begin{array}{l}
\cdot \leq m_{i} \leq B_{i} \leq M_{i}, \\
\cdot \leq y_{\min } \leq Y_{i} \leq y_{\max }, Y_{i}^{\prime} \in[-\delta y,+\delta y], i=4,5,
\end{array}\right.
$$

94where $m_{i}$ is the minimum level for the resource, $M_{i}$ the maximal biomass that can be contained 95in the ecosystem, $y_{\min }$ is the minimum level for yield for demersal and pelagic fish, and $y_{\max }$ 96the maximum level. The parameter $\delta y$ limits the evolution of the fisheries between two time 97steps. We suppose that the levels of yields of pelagic fish and demersal fish are the same. 98These constraints, which attain critical values of a "healthy" system allow one to link yield 99objectives with the principle of ecosystem persistence.

\section{The viability analysis control problem and viability kernel approximation}

101In the viability problem, the controls are the yields on pelagic fish $\left(Y_{4}\right)$, demersal fish $\left(Y_{5}\right)$, and 102the uncertainty on coefficients $r_{i j}$ and $d_{i j}$. This means that for any state of the system located in 103the viability kernel, there exist values of these parameters for which the system remains in the 104viability kernel at the next time step. Adding the constraints on the derivatives of $Y_{4}$ and $Y_{5}$ 105implies to add two dimensions to the state space, which would then be 7 . This reaches the 106current computational limits, therefore, we supposed that $Y_{4}=Y_{5}=Y$. This hypothesis is of 107course not realistic, but we thought it would nevertheless be an interesting first step.

108The viability control problem is to determine a control function:

$$
\text { with } i, j=1,2,3,4,5
$$


109which enables to keep the viability constraints (6) satisfied indefinitely. Solving this problem 110requires to determine the viability kernel, which is the set of states for which such a control 111 function exists.

112Saint Pierre (1994) proposed an algorithm to approximate the viability kernel from the 113problem defined on a grid but the result is a set of points that is viable and it requires an 114exhaustive search in the control space, which is not possible in our case because the control is 115 in the dimension 51.

116To approximate the viability kernel of the Southern Benguela ecosystem, we use a new 117algorithm (Deffuant et al., 2007) (see Appendix 1) which is built on previous work from 118Saint-Pierre (1994), using a discrete approximation of the viability constraint set $K$ by a grid. 119Its main characteristic is to use an explicit analytical expression of the viability kernel 120approximation, in order to make it possible to use standard optimization methods to compute 121the control. This analytical expression is provided by a classification procedure, the support 122vector machines (SVMs) (Vapnik, 1998, Cristianini and Show-Taylor, 2000). This algorithm 123is interesting in the case we study, because the analytical expression of the viability kernel 124allows to use optimization techniques in order to find the best evolution in high dimensional 125 control spaces.

\section{Numerical simulations}

127The donor and recipient control coefficients are derived from a mass-balanced Ecopath model 128for the ecosystem (Shannon, 2003). We use the evaluation of the parameters provided in 129(Mullon et al., 2004). Table 1 gives the values of the viability constraint set and we put $130 y_{\min }=\cdot$ tons $/ \mathrm{km}^{2}$ (no catches at all), $y_{\max }=5 \mathrm{tons} / \mathrm{km}^{2}$ (the minimal level of the biomass of 131pelagic and demersal fish, corresponding on the maximum constant value tested by Mullon et 132al. (2004)), $\delta y=0.5$ (which represents a variation of $10 \%$ of the maximal yield). The yield for 
133others species has been set to 0 , except for detritus $\left(Y_{1}=-1 \cdots\right.$ tons $/ \mathrm{km}^{2}$, which correspond of 134an import of detritus).

135The following figures present some results for given values of biomasses of each species. The 136boundaries of the axes are the constraints defined on the species represented. The 137approximation of the viability kernel is represented in grey. Inside the viability kernel, there is 138at least one viable path which allows keeping a healthy system and outside, there is no 139evolution which prevents the system from collapsing. We focus here on values of detritus 140biomass $=2000$ tons $/ \mathrm{km}^{2}$ because this ensures the existence of a viability kernel for almost all 141 the values of the others compartments. For a level of detritus biomass $=1600 \mathrm{tons} / \mathrm{km}^{2}$, given 142values of zooplankton and phytoplankton are necessary to guarantee a viable path. For lower 143detritus biomass, there is no viable path: a threshold of detritus biomass is necessary for 144ensuring a perennial system.

145In the algorithm used to approximate the viability kernel (Deffuant et al., 2007), we used a 146grid with 6 points per dimension (46000 points in total) and 1642 support vectors are 147 necessary to define the boundary of the kernel.

$148 \mathrm{We}$ focus on the effects of fisheries on demersal and pelagic fish.

\section{Effects of fisheries on demersal fish}

150Figure 2 presents a 2D slices of the viability kernel where detritus biomass $=2000$ tons $/ \mathrm{km}^{2}$, 151 phytoplankton $=100$ tons $/ \mathrm{km}^{2}$, zooplankton $=90$ tons $/ \mathrm{km}^{2}$ and for different values of pelagic 152 fish biomass. Horizontal axis represents demersal fish and vertical one the fisheries.

154The levels of pelagic fish, demersal fish and yield have an influence on the boundary of the 155viability kernel: 
156 - For low values of pelagic fish biomass, the demersal fish biomass must not be too high

157 and consequently intensive fishery must be avoid (see the circle at the top left of

$158 \quad$ Figure 2, Pelagic 5);

159 - In the same way, when the biomass of pelagic fish is high, the value of demersal fish

160 biomass must not be too low to guarantee a perennial system and some low levels of 161 catch must be avoided (see the circle at the bottom of Figure 2, Pelagic 60);

162 - For mean values of pelagic fish biomass, there is no restriction about the fisheries.

163Figure 3 presents a 2D slice of the viability kernel, when detritus biomass $=2000$ tons $/ \mathrm{km}^{2}$, 164 phytoplankton $=400$ tons $/ \mathrm{km}^{2}$ and zooplankton $=130$ tons $/ \mathrm{km}^{2}$. We note that the viability 165kernel is smaller: a high level of pelagic fish represents a non-viable situation. Again, some 166high and low levels of fisheries must be avoided. In general, when the value of zooplankton is 167higher, the viability kernel is smaller and there is no viable path starting from pelagic fish 168biomass $=60$ tons $/ \mathrm{km}^{2}$.

169 Effects of fisheries on pelagic fish

170We explore now the impact of fisheries on pelagic fish, keeping the same values for others 171 species.

172Figure 4 presents the viability kernel where detritus biomass $=2000$ tons $/ \mathrm{km}^{2}$, phytoplankton $173=90$ tons $/ \mathrm{km}^{2}$, zooplankton $=100$ tons $/ \mathrm{km}^{2}$ and for demersal fish $=5,15,30$ tons $/ \mathrm{km}^{2}$.

174We notice that fisheries affect the boundary of the viability kernel only when the demersal 175 fish biomass is too low: the more the pelagic biomass is, the more the catch can be important. 176However, whatever the level of demersal fish, the level of fisheries must be controlled to 177 guarantee a healthy system. For mean values of demersal fish, the system is not viable for low 178and high values of pelagic fish. For high values of demersal fish, the pelagic biomass must not 179be too low to guarantee the persistence of the ecosystem. 
180For high values of zooplankton (see Figure 5), the viability kernel is smaller: some values of 181demersal fish and fisheries are necessary to ensure a viable path:

182 - For low values of demersal fish, the level of fisheries must be carefully set; lower and

183 higher values of catch represent non-viable situation;

184 - For mean value of demersal fish, the system is not viable for high values of pelagic 185 fish;

186 - Fisheries have an influence for high biomass of demersal and pelagic fish: a minimum 187 level of yields is necessary to ensure ecosystem persistence (area surrounded in Figure $188 \quad 5)$

189Main results

190Our study illustrates the potential utility of the viability kernel to help the definition of viable 191 fishery policies: given values of the biomass of the five species, the viability kernel provides 192the levels of catch to avoid. In addition, the viability kernel defines some conditions in which 193the fisheries can be increased without compromising the viability. We notice that the 194maximum thresholds for fisheries used by Mullon et al. (2004) can also be increased.

\section{Discussion and conclusion}

196Solving the viability problem provides all yield policies (if any) which guarantee a perennial 197system. This study shows that it is possible and interesting to integrate fisheries as a control 198parameter of a viability problem. We made strong simplifications: we supposed the same 199yield for the two species, and we should obviously take other parameters into account, like 200social and economics issues (Mullon et al., 2004). Nevertheless, we think that this work 201illustrates the potential of the viability approach to help the definition of fishery policies.

202One of the main practical difficulties up to now with the viability theory was the lack of 203methods to solve the problem in a large number of dimensions. The use of learning 
204procedures such as SVMs gives this theory a larger practical potential. However, to deal with 205a problem of six dimensions with the current algorithm can only be done with a very rough 206precision and several improvements are necessary to get more reliable and accurate results.

207Moreover, it will be interesting to define yield strategies which allow the system to come 208 from a non-viable state back to a viable state in minimum time, or minimizing some cost. This 209relates to the definition of the resilience proposed in (Martin, 2004).

\section{Acknowledgements}

211The authors are grateful to I. Alvarez, J.P. Aubin, N. Bonneuil and P. Saint-Pierre for useful 212discussions.

\section{References}

214Aubin, J.-P., 1991. Viability theory. Birkhäuser, 543 p.

215Bene, C., Doyen, L., Gabay, D., 2001. A viability analysis for a bio-economic model. 216Ecological Economics 36(3), 385-396.

217Bonneuil, N., 2003. Making ecosystem models viable. Bulletin of Mathematical Biology 21865(6), 1081-1094.

219Cristianini, N., Shawe-Taylor, J., 2000. Support Vector Machines and other kernel-based 220learning methods, Cambridge University Press, 204 pp.

221Cury, P.M., Mullon, C., Garcia, S.M., Shannon, L.J., 2005. Viability theory for an ecosystem 222approach to fisheries. Ices journal of marine science 62(3), 577-584.

223Deffuant, G., Chapel, L., Martin, S., 2007. Approximating viability kernels with support 224vector machines. IEEE transactions on automatic control 52(5), 933-937.

225Martin, S., 2004. The cost of restoration as a way of defining resilience: a viability approach 226applied to a model of lake eutrophication. Ecology and Society 9(2). 
227Mullon, C., Curry, P., Shannon, L., 2004. Viability model of trophic interactions in marine 228ecosystems. Nat. Resource Modeling 17(1), 27-58.

229Saint-Pierre, P., 1994. Approximation of viability kernel. App. Math. Optim. 29, 187-209.

230Shannon, L., Moloney, C., Jarre, A., Field, J.G., 2003. Trophic flows in the southern 231Benguela during the 1980s and 1990s. Journal of Marine Systems 39, 83-116.

232Vapnik, V., 1998. Statistical learning theory. Wiley, $736 \mathrm{pp}$.

233Walters, C., Pauly, D., 1997. Structuring dynamic models of exploited ecosystems from 234trophic mass-balance assessments. Reviews in Fish Biology and Fisheries 7, 139-172. 


\section{Appendix 1: Algorithm of SVM viability kernel approximation}

236We consider a given time interval $d t$ and we define the set-value map $G: X \rightarrow X$

$$
G(\mathbf{x})=\{\mathbf{x}+\varphi(\mathbf{x}, \mathbf{u}) d t \text { for } \mathbf{u} \in U(\mathbf{x})\}
$$

237Considering the compact viability constraint set $K$, the viability kernel of $K$ under $G$ is the 238largest set included in $K$ such that, for any $\mathbf{x}$ in $\operatorname{Viab}(K)$ :

$$
G(\mathbf{x}) \cap \operatorname{Viab}(K) \neq \varnothing
$$

239We define a grid $K_{h}$ as a finite set of $K$ such that:

$$
\forall \mathbf{x} \in K, \exists \mathbf{x}_{h} \in K_{h} \text { such as }\left\|\mathbf{x}-\mathbf{x}_{h}\right\|<\beta(h)
$$

240At each step $n$, we define a discrete set $K_{h}^{n} \subset K_{h}^{n-1} \subset K_{h}$ and a continuous set $L\left(K_{h}^{n}\right)$ which 241 is a generalization of the discrete set and which constitutes the current approximation of the 242viability kernel. The boundary of this set is define thanks to a particularly procedure, the 243support vector machines (SVM), which is a method for data classification. Given a set of 244examples $\left\{\left(\mathbf{x}_{i}, y_{i}\right)\right\}_{i=1}^{n}$ where $\mathbf{x}_{i}$ is a real vector and $y_{i} \in\{-1,1\}$, SVM define a function $f$ 245which separates examples of each labels:

$$
f(\mathbf{x})=\sum_{i=1}^{n} \alpha_{i} y_{i} k\left(\mathbf{x}_{i}, \mathbf{x}\right)+b
$$

246with $\alpha_{i} \geq \cdot$ and $k\left(\mathbf{x}_{i}, \mathbf{x}\right)=\exp \left(\frac{-\left\|\mathbf{x}_{i}-\mathbf{x}\right\|^{2}}{r_{\sigma}{ }^{r}}\right)$.

247In (Deffuant et al., 2007), we show that it is possible to find an optimal control vector $\mathbf{u}^{*}$, 248which defines the position the most inside the current approximation of the kernel among all 249possibilities in $G(\mathbf{x})$ (we use a gradient algorithm).

250The steps of the algorithm are the following:

- Initialize the sets $K_{h}^{*}=K_{h}$ and $L\left(K_{h}^{*}\right)=K$.

- Iterate: 
- Define the discrete set $K_{h}^{n+1}$ from $K_{h}^{n}$ and $f_{n}$ as follows:

$K_{h}^{n+1}=\left\{\mathbf{x}_{h} \in K_{h}^{n}\right.$ such that $f_{n}\left(\mathbf{x}_{h}+\varphi\left(\mathbf{x}_{h}, \mathbf{u}^{*}\right) d t\right) \geq-1$

$$
\text { and } \left.\left(\mathbf{x}_{h}+\varphi\left(\mathbf{x}_{h}, \mathbf{u}^{*}\right) d t\right) \in K\right\}
$$

○ If $K_{h}^{n+1} \neq K_{h}^{n}$ then run the SVM on the learning sample obtained with the points $\mathbf{x}_{h}$ of the grid $K_{h}$, associated with the labels +1 if $\mathbf{x}_{h} \in K_{h}^{n+1}$, and with labels - 1 otherwise. Let $f_{n+1}$ be the obtained classification function. $L\left(K_{h}^{n+1}\right)$ is defined as follows:

$L\left(K_{h}^{n+1}\right)=\left\{\mathbf{x} \in K\right.$ such that $\left.f_{n+1}(\mathbf{x})=+1\right\}$

○ Else stop and return $L\left(K_{h}^{n}\right)$. 


\section{List of tables}

Tab 1 - Estimation of the minimal and maximal biomasses (Bi) for the five species 15 253

\section{List of figures}

Figure 1 - Components and structure of the Southern Benguela ecosystem. Arrows represent the flux between compartments (from Mullon et al., 2004).

Figure 2 - Approximation of viability kernel. The horizontal axis represents demersal fish, vertical axis fisheries, detritus $=2000$ tons $/ \mathrm{km}^{2}$, zooplankton $=90$ tons $/ \mathrm{km}^{2}$ and phytoplankton $=100$ tons $/ \mathrm{km}^{2}$.

Figure 3 - Approximation of viability kernel. The horizontal axis represents demersal fish, vertical axis fisheries, detritus $=2000$ tons $/ \mathrm{km}^{2}$, zooplankton $=130$ tons $/ \mathrm{km}^{2}$ and phytoplankton $=400$ tons $/ \mathrm{km}^{2}$.

Figure 4 - Approximation of viability kernel. The horizontal axis represents pelagic fish, vertical axis fisheries, detritus $=2000$ tons $/ \mathrm{km}^{2}$, zooplankton $=90$ tons $/ \mathrm{km}^{2}$ and phytoplankton $=100$ tons $/ \mathrm{km}^{2}$

Figure 5 - Approximation of viability kernel. The horizontal axis represents pelagic fish, vertical axis fisheries, detritus $=2000$ tons $/ \mathrm{km}^{2}$, zooplankton $=130$ tons $/ \mathrm{km}^{2}$ and phytoplankton $=400$ tons $/ \mathrm{km}^{2}$ 
256Tables

\begin{tabular}{|lll|}
\hline Compartment & $m_{i}\left(\right.$ tons $\left./ \mathrm{km}^{2}\right)$ & $M_{i}\left(\right.$ tons $\left./ \mathrm{km}^{2}\right)$ \\
\hline Detritus & 100 & 2000 \\
\hline Phytoplankton & 30 & 400 \\
\hline Zooplankton & 20 & 200 \\
\hline Pelagic fish & 5 & 60 \\
\hline Demersal fish & 5 & 30 \\
\hline
\end{tabular}

Tab 1 - Estimation of the minimal and maximal biomasses (Bi) for the five species. 


\section{Figures}

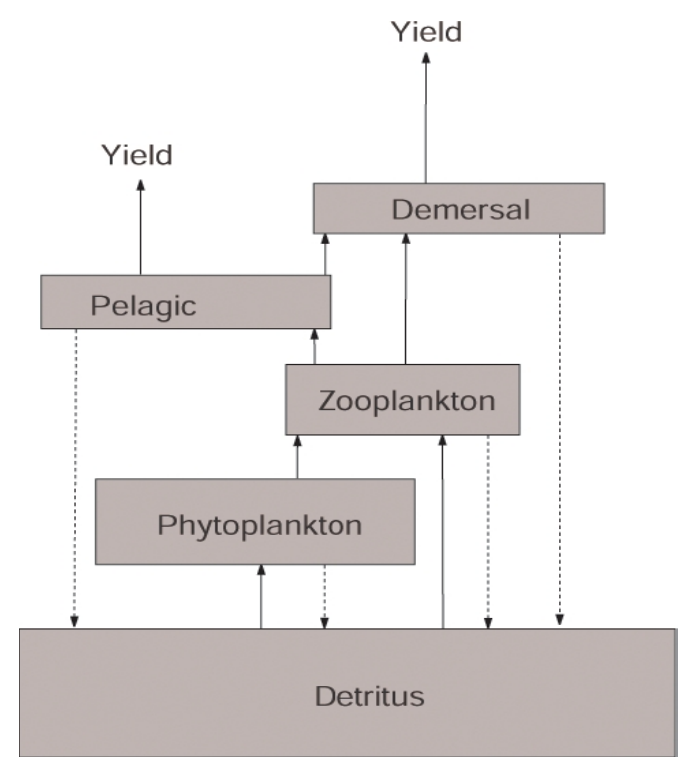

260 Figure 1 - Components and structure of the Southern Benguela ecosystem. Arrows represent the flux between compartments (from Mullon et al., 2004).

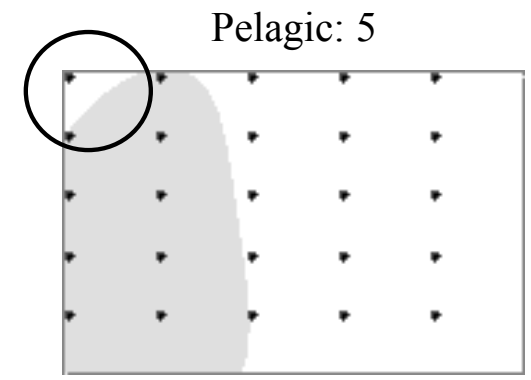

Pelagic: 30

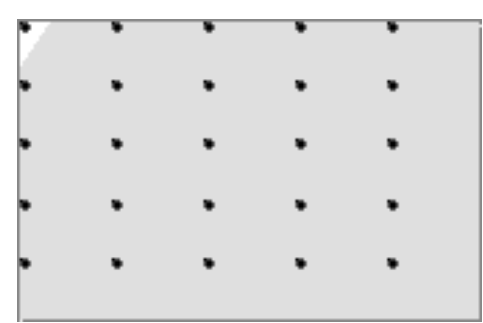

Pelagic: 60

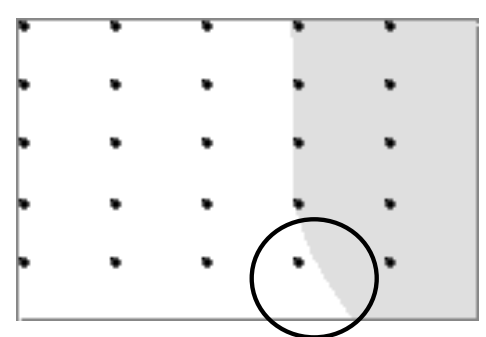

264 Figure 2 - Approximation of viability kernel. The horizontal axis represents demersal fish, vertical axis 265 fisheries, detritus $=2000$ tons $/ \mathbf{k m}^{2}$, zooplankton $=90$ tons $/ \mathbf{k m}^{2}$ and phytoplankton $=100$ tons $/ \mathbf{k m}^{2}$.

Pelagic: 5

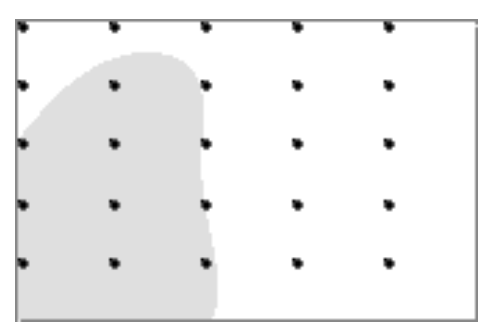

Pelagic: 30

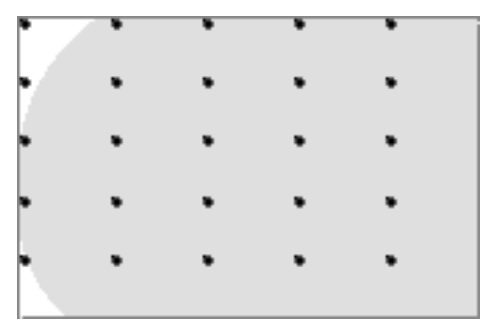

Pelagic: 60

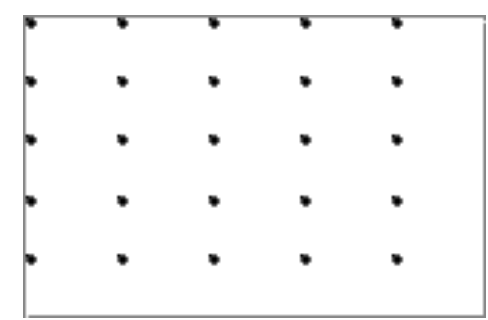

Figure 3 - Approximation of viability kernel. The horizontal axis represents demersal fish, vertical axis fisheries, detritus $=2000$ tons $/ \mathrm{km}^{2}$, zooplankton $=130$ tons $/ \mathrm{km}^{2}$ and phytoplankton $=400$ tons $/ \mathrm{km}^{2}$. 
Demersal: 5

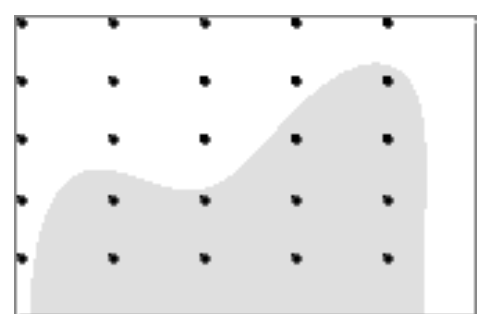

Demersal: 15

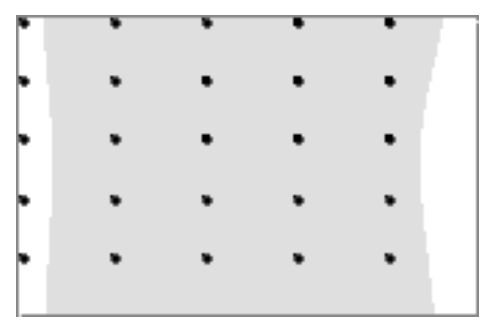

Demersal: 30

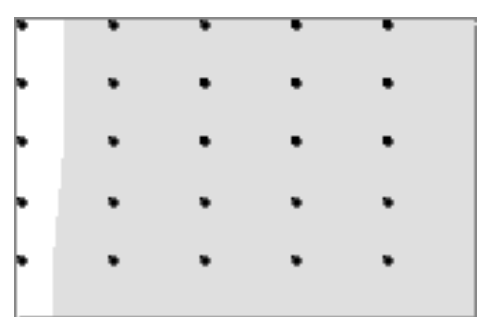

Figure 4 - Approximation of viability kernel. The horizontal axis represents pelagic fish, vertical axis fisheries, detritus $=2000$ tons $/ \mathrm{km}^{2}$, zooplankton $=90$ tons $/ \mathrm{km}^{2}$ and phytoplankton $=100$ tons $/ \mathrm{km}^{2}$.

Demersal: 5

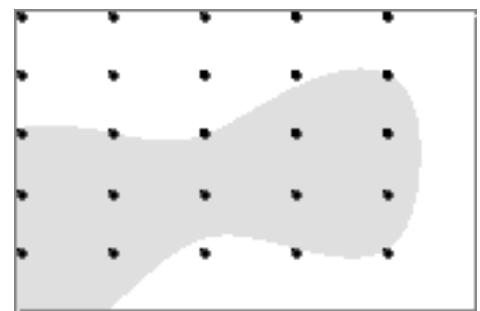

Demersal: 15

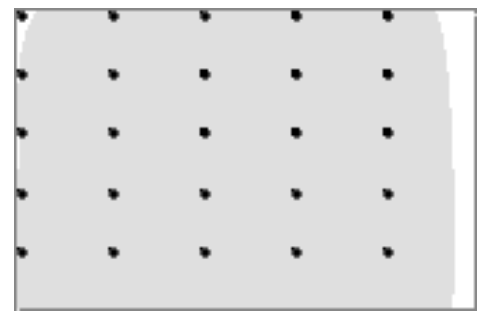

Demersal: 30

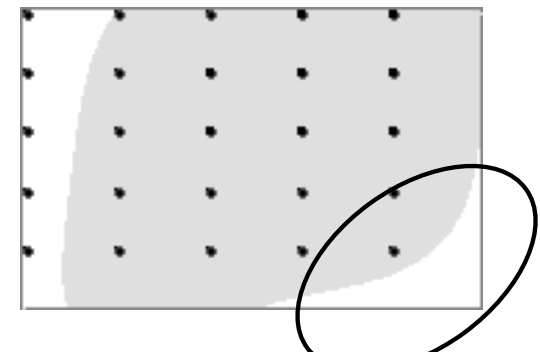

275 Figure 5 - Approximation of viability kernel. The horizontal axis represents pelagic fish, Dextieat axis fisheries, detritus $=2000$ tons $/ \mathrm{km}^{2}$, zooplankton $=130$ tons $/ \mathrm{km}^{2}$ and phytoplankton $=400$ tons $/ \mathrm{km}^{2}$. 